\title{
RESEÑA
}

\section{Mi voz se une a otras voces: desde la dicotomía hacia la lógica de la paradoja}

\author{
A propósito del texto La investigación-acción pedagógica. Experiencias y lecciones. \\ Ávila Penagos, Rafael (compilador) Bogotá, Antropos, 2003, págs, 307.
}

La responsabilidad de presentar el libro "La investigación-acción pedagógica. Experiencias y lecciones", compilado por Rafael Ávila Penagos, puede calificarse de generosidad de su parte por haberme invitado a hacerlo y de acción comprometedora por mi parte al aceptar, ya que el desafío implica -nada más ni nada menos- que nombrar y contar mi vivencia integrada de educadora-educanda, de lectora-escritora y, en unas pocas páginas, encontrar la manera de "devolverle su sabor a nuestra mejor y más vieja compañera: la palabra", al decir de Juan Goytisolo.

Me lanzo a la aventura y afirmo que recibo con beneplácito y optimismo el libro porque en él descubro que ya estamos dando los primeros pasos para trascender la llamada esquizofrenia educativa que sufrimos en el ámbito escolar y que se constituye como una combinación de disociaciones que dicotomizan los polos de múltiples dimensiones en interacción o en conflicto: entre la teoría y la práctica pedagógica, entre enseñar y aprender, entre el sujeto que supuestamente sabe -que está formado- y el sujeto que aprende y está en formación, entre el educador y el educando, entre el investigador que construye conocimiento so- bre el aula y el profesor que repite lo que otros crearon; en fin, entre quien lee y quien escribe, entre quien piensa y quien actúa.

La tradición literaria en educación asume la palabra esquizofrenia como sinónimo de disociación o separación entre los dos polos de una interacción compleja, para referirse a la distancia entre el discurso y la práctica pedagógica, en sus diferentes componentes y aspectos.

Pero hablar de esquizofrenia implica utilizar una metáfora tomada del estudio de las enfermedades mentales individuales para aplicarla a la comprensión del funcionamiento institucional y sus actores. Recuperar el origen de tal metáfora nos dará una idea de la gravedad del fenómeno encontrado en la Escuela y de la razón por la cual las experiencias como las recuperadas en el libro que hoy presentamos significan un gran avance en su superación.

Como entidad nosológica (psiquiátrica), la esquizofrenia ${ }^{1}$ es una de las enfermedades mentales más graves; algunos la siguen considerando como incurable, aunque

\footnotetext{
${ }^{1}$ Para Kraepelin, "dementia praecox"; para Bleuler "esquizofrenia"; para Freud "parafrénicos".
} 
otros encontramos hoy niveles de rehabilitación social y laboral aceptables para la convivencia y la reinserción productiva. Quien sufre esta psicosis funcional se experimenta a sí mismo como aislado del mundo y además, como si él mismo estuviese dividido en partes ajenas. Presenta un desdoblamiento radical de la conciencia y que "lleva a la consciencia deseos ocultos o reprimidos y los representa como satisfechos, encontrando completo crédito" (Freud, 1915)2. El alma del enfermo, pasa por una "disociación" que puede alcanzar una extraordinaria importancia, llegando a dividirse hasta en cuarenta o cincuenta almas parciales -según la gravedad del caso- pero usualmente, presenta al menos dos de ellas que se erigen como las almas importantes que disputan entre sí, lo cual se manifiesta en todas las actuaciones de la persona como un conflicto psíquico que escinde la personalidad en dos expresiones radicalmente enfrentadas e irreconciliables.

En este contexto, además de la dicotomía y separación de la personalidad, parece útil destacar algunos aspectos observados en el esquizofrénico: los delirios de grandeza, las alucinaciones, la falta de todo interés por el mundo exterior (personas y cosas), las estereotipias (ciertos movimientos y gestos, uniformemente repetidos), la megalomanía (hiperestimación del poder de sus deseos y sus actos mentales, omnipotencia de las ideas, fe en la fuerza mágica de las palabras y la magia como técnica contra el mundo exterior) que lleva a un estado narcisístico, es decir un estado en el cual la energía psíquica se sustrae del mundo exterior para regresar al yo del sujeto. En síntesis, el esquizofrénico expulsa del pensamiento algo determinado, disocia su conciencia, disuelve la coherencia del suceder psíquico; en esta disociación se hace manifiesta una antítesis en las representaciones psíquicas (una oposición activa de ciertos grupos de representaciones ha producido el aislamiento y la inconsciencia de otras representaciones), lo cual lleva a diversas reacciones patológicas, que produjeron la psicosis alucinatoria.

La metáfora del esquizofrénico, psicoanalíticamente comprendida a partir de la concepción dinámica que refiere a la vida anímica como un juego de fuerzas que se favorecen o estorban unas a otras, nos permite afirmar que la tradición escolar ha tenido dos almas enfrentadas que marcaron durante mucho tiempo una dicotomía - a veces radical- entre la promulgada por el saber pedagógico interiorizado como discurso y la práctica cotidiana y concreta de las interacciones del aula de clase. Así, tanto la institución como sus actores (maestros, padres y educandos), en sus discursos escritos y orales, ofrecían conceptos y pedagogías que

\footnotetext{
2 Sigmund Freud. "Adición metapsicológica a la teoría de los sueños" (1915). Obras Completas. Tomo XIV. Buenos Aires: Amorrortu Editores S.A., 1989.
}

muchas veces chocaban flagrantemente con los encuentros y desencuentros entre seres humanos de carne y hueso.

La Investigación Acción Pedagógica (participativa y educativa) nos ofrece una mediación significativa para comenzar a trascender la dicotomía entre el discurso y la acción para pasar de una lógica escindida que dicotomiza, a una lógica paradojal que reconoce a los dos polos de esta compleja interacción como serie complementaria e interdependiente. La IAP, al tomar el discurso y la acción como dos polos opuestos en movimiento dinámico, constituyéndose mutua y permanentemente, ofrece un camino para la transformación de la práctica pedagógica por medio del aprender a investigar, a formarse continuamente como maestro y redunda en la producción de un modelo vivo y cambiante de la mediación "Investigación-Acción-Pedagógica".

El libro que hoy presentamos, con sus siete textos, se constituye en una reflexión fundamentada y seria sobre experiencias y lecciones de esta vía hacia la superación de la esquizofrenia educativa: la investigaciónacción-pedagógica para que nos enfrentemos a vivir creativamente nuestra propia vivencia como educadores-aprendices-investigadores siempre en formación y en proceso de cualificación continua, sin negar los diversos niveles de conflicto que diariamente se nos presentan sino enfrentándolos con alegría para aprender de ellos.

A manera de motivación para que cada quien pueda recorrer su propio camino, he venido planteando la hipótesis de que los siete trabajos, aunque realizados en diferentes contextos y enfatizando en aspectos diversos, coinciden en la búsqueda común de formar maestros trascendiendo la esquizofrenia educativa, superando la dicotomía entre la teoría y la práctica, hacia una armonía que resulta de un discurso práctico y una práctica discursiva, hoy contada en el libro. Leerlo será una manera de descubrir, a partir de la escritura de los maestros de maestros, qué hicieron, cómo lo hicieron y que fueron aprendiendo en interacción entre maestros y discípulos para constatar así que "no hay nada más práctico que una buena teoría" (Lewin) al trabajar desde la lógica de la paradoja que lleva a una armonía oculta que surge a partir de la complementariedad e interdependencia entre los polos de cualquier interacción humana o dimensiones de lo humano.

En el primer trabajo, la voz de Luis Bernardo Peña Borrero, que "lleva el eco de otras muchas voces", aborda la formación de los educadores por la mediación de la lengua escrita que permite el registro de experiencias y resulta de un ejercicio reflexivo; se trata de que los maestros partan de, y regresen a, su vida cotidiana en el aula de clase para que mejoren su pedagogía, reflexionen y desarrollen su competencia escritural. El 


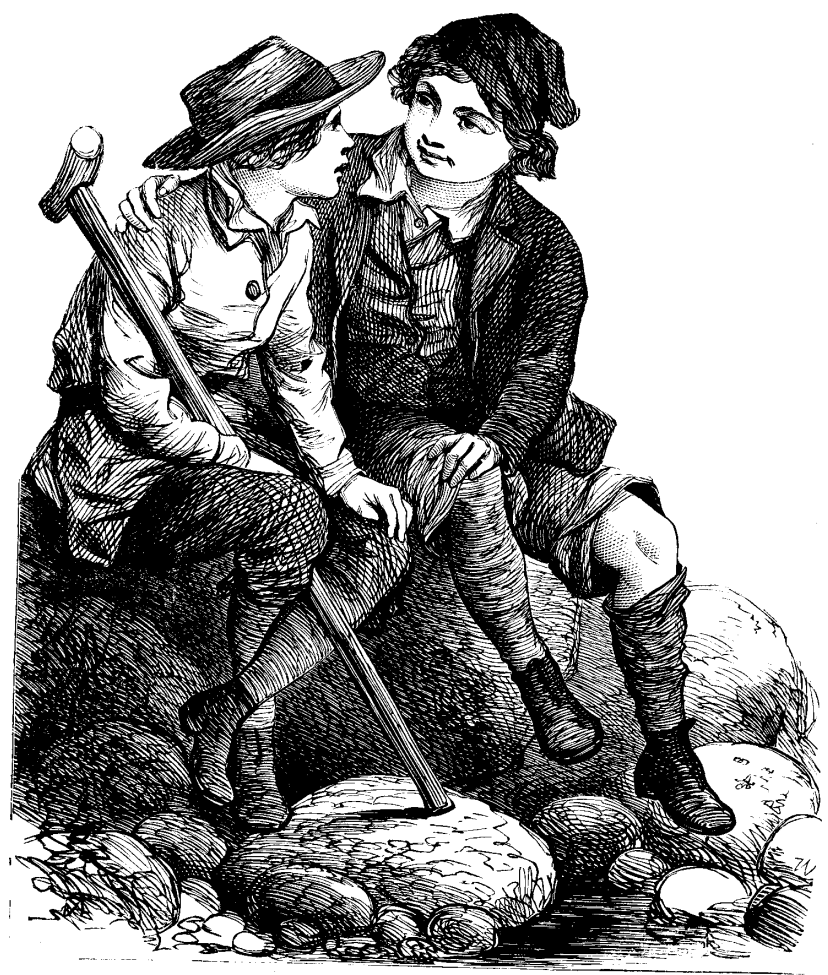

autor sistematiza un ciclo de talleres de producción escrita con maestros de diferentes regiones, en el cual el objeto de la escritura fue el saber del maestro. Este tipo de formación de maestros le permiten afirmar la importancia de encontrar "formas de escribir que dejan ver el carácter problemático de las experiencias pedagógicas, entender el contexto y las circunstancias en las que surgen, describir las escuelas reales en las que se desarrollan, ver y oir a los niños, niñas y a los demás actores que intervienen, capturar la dinámica del trabajo en el aula, no disimular las dificultades que el maestro tuvo que enfrentar para sacarlas adelante".

El texto de Bernardo Restrepo Gómez se refiere a la "capacitación de maestros en servicio" basada en la investigación adelantada por los maestros de seis cohortes sobre su propia práctica. El objeto de estudio fue doble: por un lado, la validación de la investigaciónacción pedagógica y, por el otro, proponer un modelo de capacitación de maestros en servicio basado en la investigación. El autor revisa históricamente la perspectiva de la IAP y detalla los componentes del modelo de capacitación para concluir en que la sistematización de la experiencia aporta evidencias sobre la hipótesis del maestro investigador en el campo de la práctica pedagógica ya que vivenciaron aprendizajes sobre la lógica de la investigación, la integración de la teoría con la práctica -dos aspectos tradicionalmente disociados-, comprendieron la unidad requerida entre el saber disciplinar y el saber pedagógico si se quiere abor- dar la práctica pedagógica y construyeron conscientemente, saber pedagógico.

Rafael Ávila Penagos es el vocero de las lecciones resultantes del proyecto Aluna, el cual tuve el honor de acompañar durante sus primeras etapas. Este proyecto se fue dando por aproximaciones sucesivas: desde la preocupación por la formación de lectores y escritores en general, pasando por el tema de la enseñanza de estas competencias en el ámbito escolar, hasta llegar al objeto de estudio que se desarrolló: las prácticas de formación de lectores y escritores en diferentes ámbitos disciplinarios. Ello permitió estudiar la práctica pedagógica de los maestros, al tiempo que ellos mismos se formaban como investigadores y como lectores-escritores. Considero que la construcción colectiva, magistralmente dirigida por Rafael Ávila, evidenciada desde la propia definición del objeto de estudio, el recuento de cada uno de los pasos recorridos en el proceso, con sus fortalezas y debilidades, así como los diferentes roles asumidos por los participantes, convierten a esta experiencia en un modelo de trabajo tanto para los maestros de maestros en cualquier área del conocimiento, más allá del ámbito escolar, como para los maestros y aprendices que quieran desarrollar reflexivamente su propia práctica.

Josefina Quintero Corzo y José Federmán Muñoz Giraldo, buscando la formación investigativa de educadores, aplicaron el modelo de investigación-acción-reflexión para que los practicantes-estudiantes de Licenciaturas y su asesor generaran saber pedagógico, comprendieran el sentido de su quehacer y mejoraran su práctica pedagógica. Los autores, a partir del referente teórico de la IAP, explicitan la metodología del ciclo de la espiral reflexiva en, y sobre, la acción, discuten las acciones del programa formativo en IAP, presentan sus resultados y derivan siete lecciones de la experiencia: "1) La acción educativa es un proceso investigativo; 2) es posible aprender a investigar mientras se aprende a enseñar; 3) antes de la enseñanza hay otros factores más importantes; 4) con la investigación-acción se aprende a trabajar colaborativamente; 5 ) la mejor manera de aprender a investigar es la práctica misma; 6) la investigación-acción perfecciona los procesos escriturales y la construcción de saber pedagógico; 7) todos los practicantes participantes, desde dentro del proceso de investigación-acción, han efectuado importantes transformaciones inmediatas".

El Grupo de Investigación "INAPE", por su parte, recupera escrituralmente, sus orígenes, su perspectiva teórica, su recorrido pedagógico, aprendizajes y conclusiones en tanto y en cuanto el Grupo mismo es un proyecto Investigación Acción Pedagógica que se convierte en una estrategia permanente de autoformación docente, orientada a la resignificación de la práctica pedagógica cotidiana en la Educación Superior. 
Hernando Romero Pereira realiza una serie de reflexiones relativas a la formación de educadores como docentes investigadores participativos desde, en, con y para la investigación formativa, siguiendo la tradición de los trabajos de Orlando Fals Borda, en la Costa Atlántica. El autor expresa que las sistematizaciones se han centrado en la pedagogía constructivista de la transformación y en su aspecto prescriptivo.

Cierra el libro, otro texto de Rafael Ávila Penagos centrado en el papel del tutor (o maestro de maestros) en la constitución del sujeto pedagógico. También basado en la experiencia de Aluna, profundiza en el modo de relación que mantuvo con el grupo de maestros y los diferentes roles que desempeñó con ellos.

Desde el sentido que le estoy otorgando a los textos, productos de mi co-creación entre ellos y mi interioridad, a sabiendas de que puede haber otras lecturas y otros sentidos, la principal dicotomía que el libro comienza a superar como tal, para convertirla en un movimiento entre opuestos es aquella en la cual el maestro aparece como el que enseña porque sabe y el educando como el que aprende porque no sabe. En todos los trabajos, se busca la creación de saber pedagógico y simultáneamente, la formación de maestros orientada

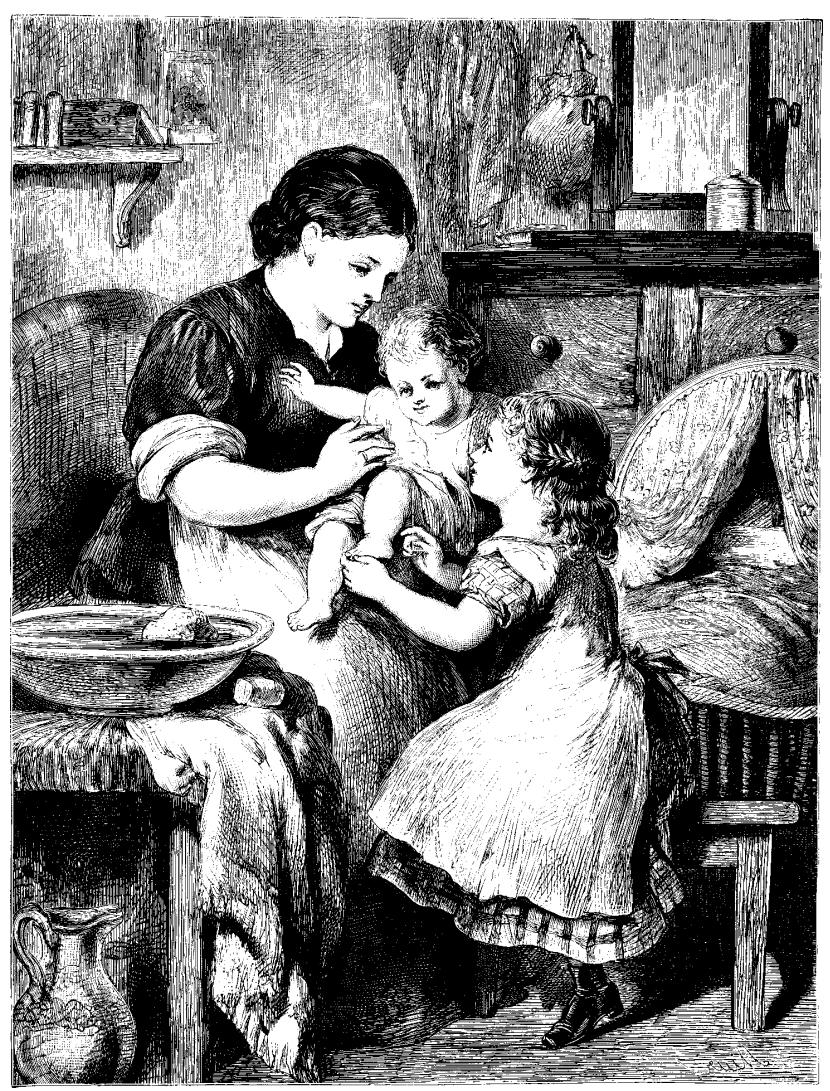

por maestros de maestros que también están formándose y, entre todos, buscando la validación de las distintas mediaciones: el ejercicio de la lengua escrita, la participación en investigación, la propia práctica pedagógica y la autoformación.

A manera de confesión, debo decir que la lectura de los capítulos me permitió, además, transformar los aportes de la Investigación-Acción-Pedagógica como mediación para la formación de investigadores cualitativos dedicados a estudiar las relaciones entre los miembros de la familia. Se trata de una transferencia de aprendizaje a otros ámbitos y tiene que ver con una anécdota personal: luego de 16 años de dedicación a la educación formal, en calidad de profesora universitaria, estoy volviendo a aprender mi oficio de educadora en espacios educativos no-formales y simultáneamente estaba leyendo este libro para estar aquí hoy en la amable compañía de todos ustedes. Rápidamente descubrí que el trabajo, aparentemente disociado de dos espacios diferentes -la pedagogía escolar y la prevención de la violencia intrafamiliar- podía ser integrado e integrador de mi identidad profesional. El libro aportó a mi formación para desarrollar mejor mis objetivos de lograr experiencias de construcción colectiva de interacción en grupo orientando la formación de investigadores en el campo de la observación y seguimiento de la familia y la niñez en la localidad de Fontibón. Estoy segura de que cada uno de ustedes, al leer el libro, podrá transferir sus lecciones a otros temas, espacios y disciplinas y contar su propia anécdota.

La unidad interna de los opuestos está lejos de ser una idea exclusiva de los místicos, orientales $u$ occidentales...

En la teoría de la relatividad, por ejemplo, los conocidos opuestos -reposo y movimientohan llegado a ser totalmente indistinguibles; dicho de otra manera, "cada uno es ambos"3.

En lo que a mi respecta, a partir de las lecciones del libro ratifico mi decisión de continuar en una búsqueda permanente y en todos los contextos, para trascender la mirada dicotómica y encontrar cada vez el camino de la lógica paradojal del movimiento dinámico entre opuestos que permite ver cualquier cambio de una manera en que toda adjetivación sobra (inevitable, positivo, negativo, problemático, etc.) porque muestra que el conflicto como proceso se da en la naturaleza y en lo humano de tal manera que todo deviene, fluye armónicamente. Cuando estamos frente a cualquier conflicto, a una oposición entre dos dimensiones humanas, si demarcamos y trazamos fronteras convertimos a los dos polos de la interacción en una dicotomía de opues-

${ }^{3}$ Ken Wilber. La conciencia sin fronteras. Aproximaciones de Oriente y Occidente al crecimiento personal. Editorial Kairós. S.A., 1984. 
tos, en lugar de ver que en el movimiento de tales opuestos, complementarios e interdependientes, finalmente surge la armonía porque todos los opuestos son aspectos inseparables de una única actividad subyacente y porque ningún opuesto podría existir sin el otro.

La armonía oculta que surge del movimiento de un opuesto al otro, a través de diferentes mediaciones como las señaladas, es un proceso, no una cosa o fenómeno estático; no existen estados, sólo procesos en el movimiento de contrarios; sólo el cambio es eterno y éste se produce entre polaridades. La armonía oculta se refiere a la armonía que existe en la contradicción de opuestos: toda dimensión humana existe con su opuesto y gracias a su opuesto (existe lo pequeño, gracias a la existencia de lo grande), aunque éste esté oculto.

La vida consiste en moverse, en el cambio, de un opuesto a otro mientras que ambos están fluyendo y en movimiento. Heráclito planteó, paradójicamente, que nadie se baña dos veces en las aguas del mismo río para mostrar el cambio, el movimiento que implica la armonía oculta. De hecho, la vida es paradójica, se mueve entre los opuestos: no es lógica como lo planteó Aristóteles (y después de él, el pensamiento más fuerte en Occidente). La doctrina de la lógica no es existencial, la paradoja de Heráclito sí lo es y no evade la contradicción (por ello, vida y muerte no son dos fenómenos, son las dos caras de una misma moneda que se mueven una hacia la otra y de ese movimiento surge la armonía oculta de la complementariedad).

En este sentido, la armonía oculta es una gestalt, concepto que alude a una armonía entre la figura y el fondo, ambos en movimiento ya que figura y fondo están en contraste, en tensión y esta tensión, precisamente, es la armonía que es parte del cosmos y por lo tanto, de la sociedad aunque nos cueste vivenciarla. La armonía oculta más profunda es la captación de que un polo (la teoría pedagógica) no puede funcionar sin el otro (la práctica pedagógica), al igual que no existiría el día si no tuviéramos la vivencia de la noche.

Esta misma concepción de Heráclito, se relaciona con la cosmovisión oriental de que la vida es movimiento y cambio, la vida es contradicción, el cosmos lo es, todo vive por medio del cambio y cambio significa, el cambio hacia la polaridad; nos movemos de un polo al otro porque de esa manera es que reconocemos que estamos aún vivos, no somos más lo que éramos en la superficie, nuestra identidad se mueve hacia otra dimensión en forma continua. $Y$ esta es la sabiduría que encontramos en los Vedas, el Buda, Lao Tzé y Chuang Tzú, entre otros. Dicho en un poema haiku de Basho:
La rana del viejo estanque salta al sonido

del agua

Estos poemas que en realidad no se explican, brindan una imagen que se vivencia; en este caso, nuestra vivencia del anterior poema es que pictóricamente nos dice que hay un viejo tanque, una rana sentada en la rivera y ... el salto de la rana. Podemos ver la caída en el agua y el sonido del agua. Pensamos que así es la vida: un tanque antiguo ...el salto de una rana, el sonido del agua y el silencio. Esto es lo que somos y lo que es el cosmos, y luego, el silencio.

Basho, al igual que Heráclito, nos traen el sonido del agua, o de un río; Heráclito, antes de decir algo, nos recuerda los sonidos del agua del río que corre y luego nos da su máxima: no podemos bañarnos dos veces en el mismo río. Ojalá en el ámbito educativo podamos afirmar que el río continúa fluyendo y que cada día es un nuevo río y que cada uno de nosotros no sea ya el mismo, manteniendo su propia identidad de educadoreducando.

Ya finalizando, reitero mi beneplácito y optimismo por la publicación del libro que hoy nos convoca y que abre las puertas para continuar trabajando con ahínco en la superación de la esquizofrenia educativa a partir de la lógica paradojal que integra la teoría y la práctica y que ilumina también, el manejo de cualquier conflicto que tengamos la valentía de enfrentar y vivir. Me despido de ustedes, recordando a Heráclito:

\section{La armonía oculta}

es mejor que la obvia.

La oposición trae concordia.

De la discordia

surge la armonía más perfecta.

Es en el cambio

que las cosas encuentran reposo.

La gente no entiende

de qué manera aquello que cambia en sí mismo, está de acuerdo consigo mismo.

Existe una armonía en la espalda que se encorva como en el caso del arco y la lira.

El nombre del arco es vida, pero su trabajo es muerte.

Fragmentos de Heráclito
Celia Spraggon Hernández

Psicoanalista, profesora-investigadora 